\title{
EDITORIAL
}

\section{Urban design and adaptative urban forms}

\author{
Mahyar Arefi ${ }^{1} \cdot$ Noha Nasser $^{1}$
}

Accepted: 26 October 2020 / Published online: 9 November 2020

(c) Springer Nature Limited 2020

We are living in times when humanity is experiencing strange and unprecedented situations. The ability (or lack thereof) to adapt characterizes the common denominator in most of the observed cases in this unprecedented era. Adaptation and resilience while overarching, imposes its own predispositions, and comes in different guises and forms from world-wide pandemics the likes of which humanity has rarely witnessed to climate change, wildfires, people fleeing war-stricken zones and an upsurge in transmigrations.

More specifically, COVID-19, the global commitment to the Paris Accord, formidable tsunamis or floods, large ghost towns dotted by skyscrapers across China (Shepard 2015), or abandoned towns and villages in some U.S. states, and desertification and global warming exemplify some of these manifestations that demand immediate global awareness and attention to these harsh realities to date.

While this issue of UDI does not necessarily address these dreadful experiences imposed on humanity, it gleans specific cases and episodes of adaptation to change that different countries bring to the fore. Each of these experiences, in their own right, brings to attention the ways in which cities from across the world have reported positive adaptative mechanisms concomitant to various internal or external impositions and by doing so, have endured abrupt outcomes, preserved and conserved their historic legacies, withstood sufferings and transitioned to optimal circumstances.

In the first article, Transitional Edges: A Conceptual Framework for Socio-Spatial Understanding of Urban Street Edges, Kevin Thwaites conceptualizes how street edges make small scale transitions and adaptations for pedestrians possible. These small but nonetheless important transformations empower place identity by enhancing the extent of its coherence and adaptiveness, spatial porosity and localized expressions. Drawing from a case study in Sheffield, the author explores the significance of these transformations

Mahyar Arefi

mahyararefi@gmail.com

1 Arlington, USA through three distinctive stages of place identity including material distinctiveness, social appropriation and spatial articulation.

While these strategies seem feasible in small transitional spaces, retail and commercial land uses represent a different context where transitions and adaptations occur. The author of the second article, Shopping Centre Morphologies in Transition: Towards a Morphological Typology of Retail Synergies, Fujie Rao explores three particular variations on a theme involving symbiosis, compounding and mutation. These synergistic possibilities range from simple to complex representations where various shopping centers or malls either synergize with the adjacent forms in their close proximity, combine with the main street into a more coherent structure, or literally mutate into other adjacent structures both formally and functionally. These complex assemblages range from new or partial formal and spatial transformations to complete new morphologies or mutations.

In the third article, Urban Revitalization with Music and Dance in the Port of Veracruz, Mexico, Fernando Gutiérrez H. unveils another innovative way of transformation or revitalization through music and dance. Plazuela de la Campana shows reappropriation and revitalization of local squares and plazas into vibrant meaningful places. The author stresses the role of refunctioning and restoring a past notorious image by a balanced mix of music and dance that can empower place by improving social interaction in a rich cultural context. Indeed, this article places much emphasis on the virtue and power of periodic events that not only help overcome past notoriety of chronic decays, but instills or 'superimposes' new and positive place identity.

In Rethinking Place-making: Aligning Placeness Factors with Perceived Urban Design Qualities (PUDQs) to improve the Built Environment in Historical Districts, Tao Jia explores the ways by which certain urban design qualities can help enhance the adaptive attributes and placeness. The urban design qualities along with place-specific attributes provide helpful reminders and points for urban designers and policymakers. In addition to walkability and space quality, attention should also be paid to spatial qualities including 
provisions for relaxation and comfort, sanitary conditions, details including hand rails, ramps and landscaping.

The last article Smart Plot Division: Generating a PlotBased Strategy for the Restoration of the Old South Historic Urban Area in Nanjing by Peng Liu represents a more traditional method of restoration, revitalization and adaptation through smart plot subdivision in Nanjing, China. The paper explores five different methods of adaptation including hybridization, redivision, megaplot restoration and redevelopment and finally small, historic patterns. The significance of these smart subdivision typologies lies in the increasing decline of predominantly small historic lots and the rise of land banking and megaplots both in development practice and policymaking.

\section{References}

Shepard, Wane. 2015. Ghost Cities of China. London: Zed Books Ltd.

Publisher's Note Springer Nature remains neutral with regard to jurisdictional claims in published maps and institutional affiliations. 